\title{
Original
}

\section{Comparison of Biweekly and Triweekly Therapy with Docetaxel and Irinotecan for Refractory or Relapsed Advanced Non-small-cell Lung cancer}

\author{
Hiroo IshidA, Takashi Hirose, Takao Shirai, \\ Kentaro OKuda, Tomohide Sugiyama, Sojiro Kusumoto, \\ Takamichi HosaKa, Kohichi Ando, Masanao NAKASHIMA, \\ Toshimitsu Yamaoka, Tsukasa OHNishi, Naoya Horichi, \\ Tohru OHMORI * and Mitsuru ADACHI
}

\begin{abstract}
We examined which regimen of triweekly or biweekly docetaxel in combination with irinotecan demonstrates superiority of the antitumor activity and toxicity in patients with refractory or relapsed advanced non-small-cell lung cancer (NSCLC). Patients with previously treated NSCLC of stage III or IV were eligible if they had a performance status of 2 or less, and were 75 years or younger. Patients were treated every 3 weeks with docetaxel $\left(50 \mathrm{mg} / \mathrm{m}^{2}\right.$ on day 2) plus irinotecan $\left(50 \mathrm{mg} / \mathrm{m}^{2}\right.$ on days 1 and 8$)$ or every 4 weeks with docetaxel $\left(33 \mathrm{mg} / \mathrm{m}^{2}\right.$ on days 2 and 16) plus irinotecan $(50 \mathrm{mg} /$ $\mathrm{m}^{2}$ on days 1 and 15$)$. Fifty patients were enrolled. Patient characteristics were not significantly different between the triweekly and biweekly arms. The overall response rates were $6.7 \%$ and $14.3 \%$, times to progression were 2 months and 3 months, median survival times were 5 months and 8 months, and 1-year survival rates were $20 \%$ and $30 \%$ in the triweekly and biweekly arms, respectively. There were no differences in response rates, TTP, and survival between arms. In the triweekly arm, grade- 3 or -4 leukopenia and diarrhea occurred more frequently than in the biweekly arm. In both arms, 2 patients had grade 3 to 4 drug-induced interstitial pneumonia but recovered after receiving steroid therapy. There were no treatment-related deaths. The biweekly arm demonstrated similar efficacy and better tolerability than the triweekly arm and can be recommended as an alternative treatment option in patients with refractory or relapsed NSCLC.
\end{abstract}

Key words : docetaxel, irinotecan, refractory or relapsed, non-small-cell lung cancer

\section{Introduction}

In two phase III trials in patients with non-small-cell lung cancer (NSCLC) previously treated with a platinum-based regimen, $75 \mathrm{mg} / \mathrm{m}^{2}$ of docetaxel administered every

The First Department of Internal Medicine, Showa University School of Medicine, 1-5-8 Hatanodai, Shinagawa-ku, Tokyo 142-8666, Japan.

* Institute of Molecular Oncology, Showa University School of Medicine. 
3 weeks resulted in a survival benefit over either best supportive care, or vinorelbine or ifosfamide ${ }^{1.2)}$. Thus, docetaxel is currently approved as a standard treatment for NSCLC refractory to platinum-based agents.

Irinotecan achieved a response of $16 \%$ in patients with advanced NSCLC previously treated with platinum-based agents and taxanes ${ }^{3)}$. Preclinical studies have demonstrated that the sequential administration of docetaxel and irinotecan results in at least supra-additive cytotoxicity against human lung cancer cell lines in vitro ${ }^{4)}$. Furthermore, the antitumor spectrum of docetaxel was completely different from that of irinotecan in an in vitro study using human lung cancer cell lines ${ }^{5)}$. No pharmacokinetic interactions are known to occur between irinotecan and docetaxel ${ }^{6.7)}$.

Various dosages of docetaxel and irinotecan have been evaluated and recommended ${ }^{6-8)}$. For phase II studies in patients with NSCLC, Adjei et al ${ }^{8)}$ recommended $160 \mathrm{mg} / \mathrm{m}^{2}$ of irinotecan and $65 \mathrm{mg} / \mathrm{m}^{2}$ of docetaxel on day 1 every 3 weeks. In contrast, Couteau et $a l^{6)}$ recommended $275 \mathrm{mg} / \mathrm{m}^{2}$ of irinotecan and $60 \mathrm{mg} / \mathrm{m}^{2}$ of docetaxel on day 1 every 3 weeks, although these amounts induced grade- 4 neutropenia in $85 \%$ of patients and sepsis in 22.5\%. Doses recommended by Masuda et $\mathrm{l}^{7)}$ for phase II studies in patients with NSCLC are $50 \mathrm{mg} / \mathrm{m}^{2}$ of irinotecan (days 1,8 , and 15) and $50 \mathrm{mg} / \mathrm{m}^{2}$ of docetaxel (day 2) administered every 28 days. However, in the phase I trial leading to the recommended dosages, leukopenia or diarrhea or both on day 15 often led to doses being omitted. Therefore, we modified the treatment schedule to $50 \mathrm{mg} / \mathrm{m}^{2}$ of irinotecan (days 1,8 ) and $50 \mathrm{mg} / \mathrm{m}^{2}$ of docetaxel (day 2) every 21 days as the triweekly docetaxel arm.

On the other hands, when docetaxel was administered every 3 weeks at a dose of 75 to $100 \mathrm{mg} / \mathrm{m}^{2}$, grade 3 or 4 neutropenia developed in more than $80 \%$ of patients, and febrile neutropenia frequently led to hospitalization ${ }^{9.10)}$. Both in vitro and in vivo studies have suggested that docetaxel is a schedule-independent drug ${ }^{11.12)}$. In a recent phase III study in previously treated NSCLC patients, weekly docetaxel of $35 \mathrm{mg} / \mathrm{m}^{2}$ demonstrated similar efficacy and better tolerability than 3-weekly docetaxel of $75 \mathrm{mg} / \mathrm{m}^{2}{ }^{13}$. Moreover, in a phase II trial of biweekly docetaxel of $50 \mathrm{mg} / \mathrm{m}^{2}$ as second-line treatment in patients with NSCLC, grade 3 or 4 neutropenia developed in only $16 \%$ of patients ${ }^{14)}$. Additionally, Yoshioka et al have recommended doses of $35 \mathrm{mg} / \mathrm{m}^{2}$ of docetaxel and $50 \mathrm{mg} / \mathrm{m}^{2}$ of irinotecan every 2 weeks for patients with inoperable or recurrent gastric cancer ${ }^{15)}$. Therefore, we decided biweekly administration of a combination of docetaxel $33 \mathrm{mg} / \mathrm{m}^{2}$ and irinotecan $50 \mathrm{mg} / \mathrm{m}^{2}$ as the biweekly docetaxel arm.

To date, no trials to compare the efficacy and toxicity of triweekly and biweekly docetaxel in combination with irinotecan for refractory or relapsed advanced NSCLC have been published. The present study assessed whether a triweekly or biweekly docetaxel treatmenet regimen was superior in terms of antitumor activity and toxicity in patients with refractory or relapsed advanced NSCLC.

\section{Patients and Methods}

\section{Eligibility criteria}

Patients with refractory or relapsed NSCLC were enrolled for the study under the following criteria : 1) histologically or cytologically confirmed NSCLC; 2) stage III or IV disease ${ }^{16)}$; 3) age of 75 years or less; 4) Eastern Cooperative Oncology Group performance status (PS) of 2 or less ${ }^{17)}$; 5) measurable or assessable lesions; 6) life expectancy of at least 8 
weeks ; 7) adequate bone marrow function (white blood cell [WBC] count from $4000 / \mu 1$ to $12,000 / \mu \mathrm{l}$, neutrophil count of $2000 / \mu \mathrm{l}$ or more, platelet count of $100,000 / \mu 1$ or more, and hemoglobin level of $9 \mathrm{~g} / \mathrm{dl}$ or more), hepatic function (total serum bilirubin level less than the upper limit of the normal range, levels of aspartate aminotransferase and alanine aminotransferase less than or equal to twice the upper limits of normal range), and renal function (serum creatinine level less than $1.5 \mathrm{mg} / \mathrm{dl}$ and creatinine clearance rate of $50 \mathrm{ml} / \mathrm{min}$ or more), with an arterial oxygen pressure of $60 \mathrm{mmHg}$ or more; and, 8) written informed consent. Patients were excluded if they had massive pleural effusion, pericardial effusion or ascites, pulmonary fibrosis, uncontrolled diabetes mellitus, severe heart disease, active infection, ileus, diarrhea, symptomatic brain metastasis, or an active secondary malignancy.

\section{Treatment schedule}

The triweekly regimen comprised intravenous drip infusions of irinotecan $\left(50 \mathrm{mg} / \mathrm{m}^{2}\right)$ given over 90 minutes on days 1 and 8 , and docetaxel $\left(50 \mathrm{mg} / \mathrm{m}^{2}\right)$ over 60 minutes on day 2 every 3 weeks (Fig. 1). The biweekly regimen involved intravenous drip infusions of irinotecan $\left(50 \mathrm{mg} / \mathrm{m}^{2}\right)$ over 90 minutes on days 1 and 15 , and docetaxel $\left(33 \mathrm{mg} / \mathrm{m}^{2}\right)$ over 60 minutes on days 2 and 16 every 4 weeks (Fig. 1). Chemotherapy was discontinued if the treatment outcome was progressive disease or if intolerable toxicity developed at any time. If there was no change after two courses, subsequent therapy was left to the discretion of the physician in charge of the patient. If 2 or more weeks passed after the scheduled start of the next cycle until these criteria were satisfied, the patient left the study at that time but was still included in the analysis.

Full doses were administered if on the day of treatment the WBC count was more than $2000 / \mu \mathrm{l}$, if the platelet count was more than $75,000 / \mu \mathrm{l}$, or if the patient had no diarrhea of grade 2 or higher. The docetaxel and irinotecan doses were reduced by $20 \%$ if the patient developed grade-4 leukopenia or neutropenia lasting 3 days or longer, grade-4 thrombocytopenia, or neutropenic fever during grade-4 neutropenia. The irinotecan dose was also reduced by $20 \%$ if the patient had diarrhea of grade 3 or higher. Chemotherapy was discontinued for grade 3 or higher nonhematological toxicity, except for alopecia, nausea / vomiting, fever, and diarrhea. All patients received premedication with dexamethasone to delay or prevent the onset of edema by docetaxel. The antiemetic medication ondansetron was given prophylactically to all patients. High-dose loperamide therapy was used to manage diarrhea induced by irinotecan. If grade-4 leukopenia or neutropenia occurred after chemotherapy, granulocyte colony-stimulating factor (G-CSF) was administered until the WBC and neutrophil counts had returned to the normal range.

\section{Evaluation}

Clinical evaluation before treatment included a baseline history and physical examination, complete differential blood count, routine chemistry profiles, chest radiography, computed tomography (CT) of the chest and abdomen, magnetic resonance imaging or CT of the brain, and radionucleotide bone scan. Tumor response was classified according to World Health Organization criteria ${ }^{18)}$. Toxicities were assessed and graded according to the National Cancer Institute Common Toxicity Criteria version 2.019). All patients who received at least two cycles of chemotherapy were assessable for response, and all patients who received at least one cycle of chemotherapy were assessable for toxicity and survival. 


\begin{tabular}{|c|c|c|c|c|c|c|}
\hline \multicolumn{7}{|l|}{ Triweekly arm } \\
\hline $\begin{array}{l}\text { Irinotecan } 50 \mathrm{mg} / \mathrm{m}^{2} \\
\text { (Days } 1 \text { and } 8 \text { ) }\end{array}$ & $\downarrow$ & & $\downarrow$ & & & \\
\hline $\begin{array}{l}\text { Docetaxel } 50 \mathrm{mg} / \mathrm{m}^{2} \\
\text { (Day 2) }\end{array}$ & & $\downarrow$ & & & & \\
\hline Days & 1 & 2 & 8 & 15 & & 21 \\
\hline \multicolumn{7}{|l|}{ Biweekly arm } \\
\hline $\begin{array}{l}\text { Irinotecan } 50 \mathrm{mg} / \mathrm{m}^{2} \\
\text { (Days } 1 \text { and } 15 \text { ) }\end{array}$ & $\downarrow$ & & & $\downarrow$ & & \\
\hline $\begin{array}{l}\text { Docetaxel } 33 \mathrm{mg} / \mathrm{m}^{2} \\
\text { (Day } 2 \text { and } 16)\end{array}$ & & $\downarrow$ & & & $\downarrow$ & \\
\hline Days & 1 & 2 & 8 & 15 & 16 & 21 \\
\hline
\end{tabular}

B.

Triweekly arm

Days 1 and 8

5HT3 antagonist and dexamethasone intravenous drip infusion $\downarrow$

Irinotecan $50 \mathrm{mg} / \mathrm{m}^{2}$ intravenous drip infusion in 90 minutes

Day 2

5HT3 antagonist and dexamethasone intravenous drip infusion

$\downarrow$

Docetaxel $50 \mathrm{mg} / \mathrm{m}^{2}$ intravenous drip infusion in 60 minutes

Biweekly arm

Days 1 and 15

5HT3 antagonist and dexamethasone intravenous drip infusion $\downarrow$

Irinotecan $50 \mathrm{mg} / \mathrm{m}^{2}$ intravenous drip infusion in 90 minutes

Day 2 and 16

5HT3 antagonist and dexamethasone intravenous drip infusion $\downarrow$

Docetaxel $33 \mathrm{mg} / \mathrm{m}^{2}$ intravenous drip infusion in 60 minutes

Fig. 1. Treatment schedule

\section{Statistical Methods}

Time to progression (TTP) was defined as the period from the start of treatment to identifiable disease progression. Survival time was measured from the start of the present treatment until death or last follow-up. The Kaplan-Meier method was used to calculate survival curves. A log-rank test was used to compare Kaplan-Meier curves for survival and TTP. 
Table 1. Patient characteristics

\begin{tabular}{lcc}
\hline & $\begin{array}{c}\text { Triweekly } \\
\text { arm }\end{array}$ & $\begin{array}{c}\text { Biweekly } \\
\text { arm }\end{array}$ \\
\hline Total number of patients & 15 & 35 \\
Sex (M / F) & $11 / 4$ & $27 / 8$ \\
Median age (range) & $59(41-75)$ & $64(41-75)$ \\
Performance status at relapse (0/1/2) & $0 / 8 / 7$ & $2 / 15 / 18$ \\
Stage at relapse (III / IV) & $2 / 13$ & $6 / 29$ \\
Histological type & & \\
Adenocarcinoma & 11 & 25 \\
Squamous cell carcinoma & 2 & 7 \\
Other & 2 & 3 \\
Number of prior regimens of chemotherapy $(1 / 2)$ & $11 / 4$ & $27 / 8$ \\
Thoracic radiation therapy (yes / no) & $9 / 6$ & $16 / 19$ \\
Response to front-line chemotherapy & & \\
$\quad$ Complete response & 0 & 0 \\
Partial response & 6 & 12 \\
$\quad$ No change & 3 & 9 \\
Progressive disease & 6 & 13 \\
$\quad$ Not assessable & 0 & 1 \\
Median time off chemotherapy & 4 & 3 \\
\hline
\end{tabular}

\section{Results}

\section{Patients characteristics}

From January 2002 through February 2006, 50 patients were considered eligible for this study (Table 1). Patient characteristics were not significantly different between the biweeklyand triweekly-regimen arms. No patients had undergone surgical resection, but all had received a platinum-containing regimen as first-line chemotherapy. Of the triweekly arm (15 patients), 8 patients had received cisplatin and vinorelbine, 6 patients had received nedaplatin and gemcitabine, 1 patient had received cisplatin and etoposide, 1 patient had received carboplatin and irinotecan, and 3 patients had received gemcitabine. Four (26.7\%) of these 15 patients had previously received two regimens of other chemotherapy. Nine patients were refractory and 6 patients were relapsed cases. In the biweekly arm (35 patients), 12 patients had received cisplatin and vinorelbine, 11 patients had received nedaplatin and paclitaxel, 10 patients had received nedaplatin and gemcitabine, 1 patient had received cisplatin and etoposide, and 1 patient had received carboplatin and paclitaxel. Eight (23\%) of these 35 patients had previously received two regimens of other chemotherapy. Twentythree patients were refractory and 12 patients were relapsed cases.

\section{Treatment response and survival}

The overall response rate was $6.7 \%$ (95\% confidence interval, $0.2-31.9 \%$ ) in the triweekly arm and $14.3 \%$ (95\% confidence interval, 4.8-30.3\%) in the biweekly arm (Table 2). Response rates between arms were not significantly different $(P=0.45)$.

Survival analysis was performed at 5 months median follow-up for all assessable patients. 
Table 2. Response Rate

\begin{tabular}{|c|c|c|c|c|c|}
\hline & \multicolumn{2}{|c|}{ Triweekly arm } & \multicolumn{2}{|c|}{ Biweekly arm } & \multirow[t]{2}{*}{$P$ value } \\
\hline & $\begin{array}{l}\text { Number } \\
(n=15)\end{array}$ & $\%$ & $\begin{array}{l}\text { Number } \\
(\mathrm{n}=35)\end{array}$ & $\%$ & \\
\hline Complete response & 0 & 0 & 0 & 0 & \\
\hline Partial response & 1 & 6.7 & 5 & 14.3 & 0.45 \\
\hline No change & 7 & 46.7 & 16 & 45.7 & \\
\hline Progressive disease & 7 & 46.7 & 12 & 34.3 & \\
\hline Not assessable & 0 & 0 & 2 & 5.7 & \\
\hline
\end{tabular}

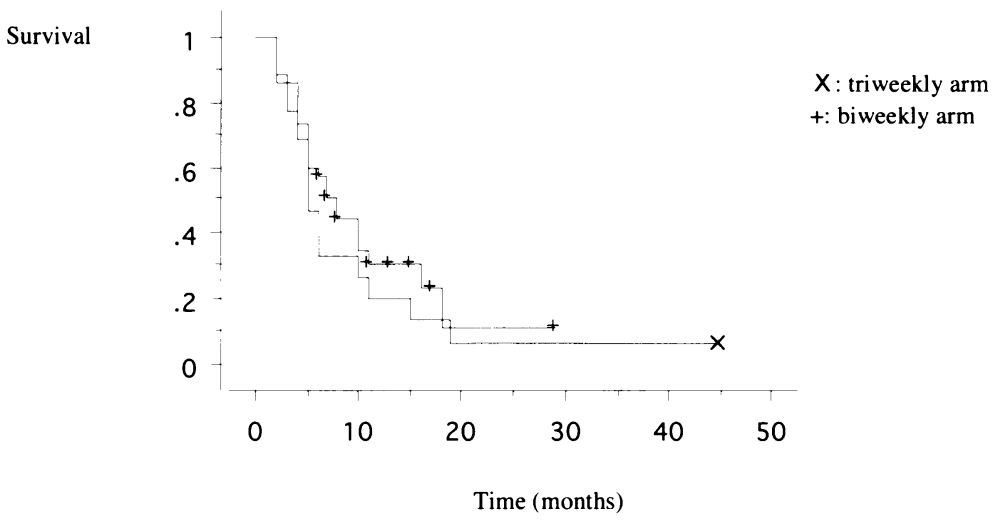

Fig. 2. Overall survival time from the start of docetaxel and irinotecan

At the time of analysis, 11 patients (22\%) were still alive and none had been lost to follow-up. The TTP from the start of the regimen was 2 months in the triweekly arm and 3 months in the biweekly arm, with no significant difference between arms $(P=0.05)$. The median survival time (MST) from the start of this regimen was 5 months in the triweekly arm and 8 months in the biweekly arm (Fig. 2). The 1-year survival rate from the start of treatment was $20 \%$ in the triweekly arm and $30 \%$ in the biweekly arm. Overall survival did not differ significantly between the arms $(P=0.45)$.

\section{Toxicity}

A median of two courses was given per patient (range, 1 to 4). Although myelosuppression was the most frequent toxicity overall, no patients had any associated severe complications (Table 3). Grade-3 or -4 leukopenia and diarrhea occurred more frequently in the triweekly arm than in the biweekly arm, and although grade- 3 infections due to the neutropenia developed in $13 \%$ of the triweekly arm and in $6 \%$ of the biweekly arm patients, all responded to antibiotics. Two patients in both groups developed grade- 3 to -4 drug-induced interstitial pneumonia during the first or second cycle but recovered following steroid pulse therapy and supplemental oxygen. These patients showed no evidence of interstitial shadow on pretreatment chest CT films. There were no treatment-related deaths. 
Table 3. Toxicity of grade 3 or 4

\begin{tabular}{lcrcrr}
\hline & \multicolumn{2}{c}{ Triweekly arm } & \multicolumn{2}{c}{ Biweekly arm } & $P$ value \\
Toxicity & Number & $\%$ & Number & $\%$ & \\
\hline Leukopenia & 13 & 87 & 17 & 49 & 0.01 \\
Neutropenia & 12 & 80 & 19 & 54 & 0.08 \\
Thrombocytopenia & 0 & 0 & 0 & 0 & $>0.99$ \\
Anemia & 3 & 20 & 9 & 25 & 0.66 \\
Nausea/Vomiting & 0 & 0 & 0 & 0 & $>0.99$ \\
Diarrhea & 3 & 20 & 0 & 0 & 0.01 \\
Infection & 2 & 13 & 2 & 6 & 0.36 \\
Elevation of transaminase & 0 & 0 & 1 & 3 & 0.51 \\
Electrolyte & 0 & 0 & 0 & 0 & $>0.99$ \\
Pulmonary & 2 & 13 & 2 & 6 & 0.36 \\
Neurologic peripheral & 0 & 0 & 0 & 0 & $>0.99$ \\
\hline
\end{tabular}

\section{Dose intensity}

During the 27 courses of chemotherapy in the triweekly arm, 20 (74\%) doses of irinotecan were cancelled on day 8 , predominantly due to neutropenia, although 16 of the 20 cancelled doses could be administered on day 15 instead. The actual delivered mean individual doses for docetaxel and irinotecan were $16.3 \mathrm{mg} / \mathrm{m}^{2}$ (97.6\% of planned) and $29.6 \mathrm{mg} / \mathrm{m}^{2}(88.9 \%$ of planned), respectively. In the biweekly arm, the actual delivered mean individual doses for docetaxel and irinotecan were $15.7 \mathrm{mg} / \mathrm{m}^{2}\left(95.4 \%\right.$ of planned) and $23.9 \mathrm{mg} / \mathrm{m}^{2}(95.4 \%$ of planned), respectively.

\section{Discussion}

Docetaxel is currently approved as a standard treatment for NSCLC cases refractory to platinum-based agents, based on two phase III trials. However, these trials yielded unsatisfactory results, with response rates of approximately 7\%, as well as TTPs of 10.6 and 8.5 weeks, MSTs of 7.5 and 5.7 months, and 1-year survival rates of $37 \%$ and $32 \%$, respectively ${ }^{1.2)}$. The field therefore needs new treatment regimens that are less toxic and more effective for relapsed or refractory NSCLC.

The present study yielded overall response rates of $6.7 \%$ and $14.3 \%$, TTPs of 2 and 3 months, MSTs of 5 and 8 months, and 1-year survival rates of $20 \%$ and $30 \%$ with the triweekly and biweekly regimens, respectively. There were no differences in response rate, TTP, and survival between the two arms; however, grade- 3 or -4 leukopenia and diarrhea occurred more frequently in the triweekly arm compared to the biweekly arm. We concluded that the biweekly arm demonstrated similar efficacy and better tolerability than the triweekly arm in patients with refractory or relapsed NSCLC.

Several studies have assessed the combination of docetaxel and irinotecan in secondline treatments of NSCLC, with overall response rates ranging from $6 \%$ to $20 \%$, MSTs of 6.2 to 8 months, and 1-year survival rates of $24 \%$ to $37 \%{ }^{20-23)}$. Our results thus compare favorably with previous trials in NSCLC patients, although caution must be exercised in making direct comparisons because the other studies used different prognostic factors for patient inclusion. 
Toxicity rates in our study also compare favorably with recently published phase II or III trials of second-line treatment for NSCLC. Rates of grade-3 to -4 neutropenia, thrombocytopenia, and anemia ranged from $0-85 \%, 0-17 \%$, and $0-23 \%$, respectively ${ }^{1,2.20-25)}$, while the rate of dose-limiting, grade-3 to -4 diarrhea ranged from $6-39 \%$ of patients across several trials ${ }^{7.820-23)}$. In our study, leukopenia and diarrhea occurred more frequently with the triweekly regimen compared to the biweekly arm. This was consistent with a previous report of weekly docetaxel delivering a significantly improved toxicity profile compared with triweekly docetaxel ${ }^{20)}$. Although grade-3 drug-induced interstitial pneumonia developed in 2 patients in both arms in the present study, it was resolved with steroid pulse therapy, and pretreatment chest CT showed no evidence of interstitial shadow. Drug-induced interstitial pneumonia was not reported in previous studies of combined docetaxel and irinotecan ${ }^{7,8,20-23)}$. The reason for this side effect in our study is unknown. However, all complications were manageable, and there were no treatment-related deaths.

In conclusion, this is the first study to our knowledge that compares the efficacy and toxicity of biweekly and triweekly drug treatments using a combination of docetaxel and irinotecan for refractory or relapsed advanced NSCLC. The biweekly arm demonstrated similar efficacy and better tolerability than the triweekly arm and can be recommended as a feasible alternative treatment option in these patients.

\section{References}

1) Fossella FV, Devore R, Kerr RN, Crawford J, Natale RR, Dunphy F, Kalman L, Miller V, Lee JS, Moore M, Gandara D, Karp D, Vokes E, Kris M, Kim Y, Gamza F and Hammershaimb L: Randomized phase III trial of docetaxel versus vinorelbine or ifosfamide in patients with advanced non-small cell lung cancer previously treated with platinum-containing chemotherapy regimens. J Clin Oncol 18 : 2354-2362 (2000)

2) Shepherd FA, Dancey J, Ramlau R, Mattson K, Gralla R, Rourke MO, Levitan N, Gressot L, Vincent M, Burkes R, Coughlin S, Kim Y and Berille J : Prospective randomized trial of docetaxel versus best supportive care in patients with non-small-cell lung cancer previously treated with platinum-based chemotherapy. $J$ Clin Oncol $18: 2095-2103$ (2000)

3) Sanchez R, Esteban E, Palacio I, Fernandez Y, Muniz I, Vieitez JM, Fra J, Blay P, Villanueva N, Una E, Mareque B, Estrada E, Buesa JM and Lacave AJ : Activity of weekly irinotecan (CPT-11) in patients with advanced non-small cell lung cancer pretreated with platinum and taxanes. Invest New Drugs 21:459-463 (2003)

4) Okishio K, Kudoh S and Hirata K: Schedule dependent additive effect of docetaxel and irinotecan in vitro. Jpn J Cancer Res 86 Suppl: 619 (1995)

5) Matsushita A, Tabata M, Ueoka H, Kiura K, Shibayama T, Aoe K, Kohara H and Harada M: Establishment of a drug sensitivity panel using human lung cancer cell lines. Acta Med Okayama 53:67-75 (1999)

6) Couteau C, Risse ML, Ducreux M, Lefresne-Soulas F, Riva A, Lebecq A, Ruffie P, Rougier P, Lokiec F, Bruno $\mathrm{R}$ and Armand JP: Phase I and pharmacokinetic study of docetaxel and irinotecan in patients with advanced solid tumors. J Clin Oncol $18: 3545-3552$ (2000)

7) Masuda N, Negoro S, Kudoh S, Sugiura T, Nakagawa K, Saka H, Takada M, N II tani H and Fukuoka M: Phase I and pharmacologic study of docetaxel and irinotecan in advanced non-small-cell lung cancer. $J$ Clin Oncol 18 : 2996-3003 (2000)

8) Adjei AA, Klein CE, Kastrissios H, Goldberg RM, Alberts SR, Pitot HC, Sloan JA, Reid JM, Hanson LJ, Atherton P, Rubin $\mathbf{J}$ and Erlichman $\mathrm{C}$ : Phase $\mathbf{I}$ and pharmacokinetic study of irinotecan and docetaxel in patients with advanced solid tumors: preliminary evidence of clinical activity. J Clin Oncol 18:1116-1123 (2000)

9) Fossella FV, Lee JS, Shin DM, Calayag M, Huber M, Perez-Soler R, Murphy WK, Lippman S, Benner S, Glisson B, Chasen M, Hong WK and Raber M: Phase II study of docetaxel for advanced or metastatic platinum-refractory non-small-cell lung cancer. J Clin Oncol 13 : 645-651 (1995)

10) Gandara DR, Vokes E, Green M, Bonomi P, Devore R, Comis R, Carbone D, Karp D and Belani C: Activity of docetaxel in platinum-treated non-small-cell lung cancer: results of a phase II multicenter trials. $J$ Clin Oncol $18: 131-135$ (2000)

11) Bissery MC, Guenard D, Gueritte-Voegelein F and Lavelle F : Experimental antitumor activity of taxotere (RP 
56976, NSC 628503), a taxol analogue. Cancer Res 51:4845-4852 (1991)

12) Verweij J, Clavel $M$ and Chevalier B : Paclitaxel (Taxol) and docetaxel (Taxotere): not simply two of a kind. Ann Oncol 5 : 495-505 (1994)

13) Shuette W, Nagel S, Blankenburg T, Lautenschlaeger C, Hans K, Schmidt EW, Dittrich I, Schweisfurth H, Weikersthal LFV, Raghavachar A, Reisig A and Serke M: Phase III study of second-line chemotherapy for advanced non-small-cell lung cancer with weekly compared with 3-weekly docetaxel. J Clin Oncol 23:83898395 (2005)

14) Vazquez S, Grande C, Amenedo M, Firvida JL, Lazaro M, Alonso G, Cureil T, Huidobro G, Mel JR and Ramos M: Biweekly docetaxel as second-line chemotherapy of patients with advanced non-small cell lung cancer: a phase II study of the Galician Lung Cancer Group (GGCP 006-00). Anti-Cancer Drugs 15:489-494 (2004)

15) Yoshioka T, Sakata Y, Terashima M, Sekikawa K, Gamoh M, Mitachi Y, Saitoh S and Kanamaru R : Biweekly administration regimen of docetaxel combined with CPT-11 in patients with inoperable or recurrent gastric cancer. Gastric Cancer $6: 153-158$ (2003)

16) Mountain CF : Revisions in the international system for staging lung cancer. Chest $111: 1710-1717$ (1997)

17) Oken MM, Creech RH, Tormey DC, Horton J, Davis TE, McFadden ET and Carbone PP: Toxicity and response criteria of the Eastern Cooperative Oncology Group. Am J Clin Oncol 5:649-655 (1982)

18) World Health Organization: WHO Handbook for Reporting Results of Cancer Treatment. World Health Organization, Geneva (1979) (WHO offset publication; no. 48)

19) National Cancer Institute: Guidelines for Reporting Adverse Drug Reactions. Division of Cancer Treatment, National Cancer Institute, Bethesda (1998)

20) Font A, Sanchez JM, Taron M, Martinez-Balibrea E, Sanchez JJ, Manzano JL, Margeli M, Richardet M, Barnadas A, Abad A and Rosell R: Weekly regimen of irinotecan/docetaxel in previously treated non-small cell lung cancer patients and correlation with uridine diphosphate glucuronosyltransferase 1A1 (UGT1A1) polymorphism. Invest New Drugs $21: 435-443$ (2003)

21) Grossi F, Fasola G, Rossetto C, Spizzo R, Meduri S, Sibau A, Vigevani E, Tumolo S, Adami G, Sacco C, Recchia L, Rizzato S, Ceschia $\mathrm{T}$ and Belvedere $\mathrm{O}$ : Phase II study of irinotecan and docetaxel in patients with previously treated non-small-cell lung cancer: an alpe-adria thoracic oncology multidisciplinary group study (ATOM 007). Lung Cancer $52: 89-92$ (2006)

22) Pectasides D, Pectasides M, Farmakis D, Kostopoulou V, Nikolaou M, Gaglia A, Koumpou M, Mylonakis N, Xiros N, Economopoulos $\mathrm{T}$ and Raptis SA : Comparison of docetaxel and docetaxel-irinotecan combination as second-line chemotherapy in advanced non-small-cell lung cancer: a randomized phase II trial. Ann Oncol 16: 294-299 (2005)

23) Wachters FM, Groen HJM, Biesma B, Schramel FMNH, Postmus PE, Stigt JA and Smit EF : A randomized phase II trial of docetaxel vs docetaxel and irinotecan in patients with stage III B-IV non-small-cell lung cancer who failed first-line treatment. Br J Cancer $17: 15-20$ (2005)

24) Fossella FV, Lee JS, Shin DM, Calayag M, Huber M, Perez-Soler R, Murphy WK, Lippman S, Benner S, Glisson B, Chasen M, Hong WK and Raber M: Phase II study of docetaxel for advanced or metastatic platinum-refractory non-small-cell lung cancer. J Clin Oncol 13 : 645-651 (1995)

25) Gandara DR, Vokes E, Green M, Bonomi P, Devore R, Comis R, Carbone D, Karp D and Belani C: Activity of docetaxel in platinum-treated non-small-cell lung cancer: results of a phase II multicenter trials. $J$ Clin Oncol 18 : 131-135 (2000)

[Received January 18, 2007 : Accepted January 25, 2007] 